\title{
TABUS LINGÜISTICOS
}

\section{R. F. Mansur Guérios}

(Continuaçāo)

\section{TABUS EM NOMES DE MORTOS *}

Entre os indigenas, pronunciar o nome de um morto é atrair desgraças. Por grande necessidade, pode-se, entre as tribos da Austrália central, citar o nome, porém, em voz baixa, que não possa o espírito ouvi-lo. Do contrário, êste fica indignado pelo desrespeito e virá atormentá-los em sonhos. A proibição, em certas tribos, é só para as mulheres ou não é tanto para os homens.

Acreditavam os Australianos que, se viessem a adotar nome de defunto, não viveriam muito. Supunham, provàvelmente, que o xará viria, sob forma de fantasma, buscá-lo para levá-lo à região das almas. A repugnância ao nome do falecido é tal, que o xará sobrevivente não o usa mais; substitui-o por outro. O novo, contudo, será trocado, se houver outro homônimo que venha a falecer. Tal igualdade se dá nas Novas Gales do Sul.

Certas tribos de Vitória (Austrália), não se empregam os nomes usuais dos parentes no período de luto; são substituidos por têrmos gerais prescritos em protocolo.

Os Narrinieris (Austrália) tabuízam o nome do extinto provisòriamente, i. é, até que o cadáver haja apodrecido. Outras tribos procedem a cerimônias (dessecam o cadáver no fogo), etc.

Ainda na Austrália, entre os Tiuis (Tíwi), das ilhas Melville e Bathurst (126), não se permite, com a morte de alguém, usar

* Resumimos o valioso material coletado por J. G. FRAZER, Tabou ef les Périls de l'Ame. Quando de outros AA., èstes são declarados.

126. J. G. FRAZER, Totemica, Londres, 1937, p. 19-20. 
os vários nomes que êste possua. Vedados ficam os vocábulos que hajam apenas qualquer semelhança fônica com os nomes do falecido, menos, curiosamente, aquêles empregados na linguagem sagrada. Não escapam ao tabu as palavras inglêsas em uso entre êles, as quais tenham também sílabas iguais às dos nomes proibidos.

A curiosidade maior consiste em que ficam tabuizados igualmente os nomes que o morto haja dado não só a seus filhos, senão ainda aos de outros. Desde o momento do falecimento, a criança que recebeu um nome do morto, fica vedado empregá. -lo, até que obtenha outro em outro lugar. Mas aí não se estende - tabu a qualquer palavra semelhante.

Morto um indivíduo de nome Mulankina, ficou, p. ex. interditada a palavra comuníssima mulikina, "cheio, muito". Com a morte de um rapaz chamado Tipuki, tabuizou-se 0 inglês tobacco.

Em Taiti, a substituição do nome da coisa pelo do rei é provisória; morto o rei, desaparecem os têrmos novos e voltam-se aos antigos.

Entre os labins (Nova Guiné), a declaração do nome dé um falecido interromperia a refeição de frutas dos espíritos, para Perturbar os vivos.

Em Logea (ilha do arquipólago Samarai, costa da Nova Guiné), dizer o nome do morto aos parentes é tamanho insulto que se faz mister vingar com a morte do profanador, ou de um dos parentes ou amigos. Essa violação e o homicidio são as causas principais das guerras nessa região.

Entre os Massais, é ofensa grave declarar a denominação do extinto perante os parentes. Substituem-na por nome novo, que, então, podem torná-lo público. Destarte o defunto não o conhece e não responderá quando o ouvir. E com o falecimento de um xará, o sobrevivente muda de nome.

Os Tuaregues (deserto de Saara) receiam a volta do espirito do defunto; evitam-na mudando o local do acampamento 
após o falecimento, abstendo-se constantemente de pronunciar o nome do finado e de tudo que poderia ser evocação ou lembrança do mesmo. Ao contrário dos Árabes, não designam os filhos pelo patronímico (lussuf ibn Butrus, "José filho de Pedro").

Os nativos de Nicobar ( $i$ lhas da baía de Bengala) mudam o nome para fugir às importunações dos entes sobrenaturais, além de disfarçarem, raspando a cabeça, com o que não pode o espírito identificá-los.

Entre certas tribos das Novas Gales do Sul não se transmitem de geração a geração as cantigas para dança, pois, morto o poeta, seu nome é tabu e deixam-se de cantar suas canções.

$\mathrm{Na}$ Lapônia (Europa setentrional), à mulher na época do parto, aparece, geralmente em sonho, um antepassado para lhe dizer qual o morto deverá renascer na criança e daí o nome que terá.

Segundo Estrabão, o costume de evitar pronunciar os nomes dos mortos era observado, na antiguidade, pelos Albaneses do Cáucaso.

Em certas tribos da América do Norte, todos os tocaios do defunto abandonam o nome, adotando outro em solenes cerimônias.

Entre os Tuanas, povo de língua sálixe ("salish"), no canal de Hood, Washington ocidental, pela morte de um adulto da classe superior, o seu nome e as palavras que se the assemelham, são tabuizados. Mas essa tabuização se realiza cerimoniosamente em festa patrocinada pelo grupo aparentado ao morto. Há, então, um locutor que anuncia a finalidade da cerimônia, menciona a palavra que se põe fora do uso, declara que o expressá-la causa aflição aos parentes do falecido, e, por fim, indica o têrmo substituto a ser empregado em lugar do vocábulo tabuizado. Assim, pela morte de um fulano chamado xá twas, trocou-se xá txat, "pato selvagem" para há habched, "pé vermelho" (127).

127. W. W. ELMENDORF, Word Taboo and Lexical Change in Coast Salish in "Intern. Journal of American Linguistics", v. XVII, n. ${ }^{\circ} 4,1951$, p. 205. 
Entre os Caroques (Califórnia) é crime gravíssimo citar o parente falecido; insulto abominável aos sobreviventes. $O$ culpado expia o delito mediante multa ou a vida.

Com os Puialupes (América do Norte) a observância ao tabu se ameniza após alguns anos, esquecidos do desenlace, mas se o defunto era um guerreiro famoso, pode-se dar o seu nome a um dos descendentes.

Entre os Atiuoindarões (Canadá) há cerimônia da "ressurreição dos mortos famosos". Consiste na escolha de alguém, dotado das mesmas qualidades e virtudes, que se finge de morto, e é levantado do túmulo com o mesmo nome do falecido. Igual fato Se verifica entre os Hurōes (Canadá).

Os Chuckchees (estreito de Béringue) - pela morte da mãe, trocam o nome do filho mais jovem para que a alma (todos os mortos passam a espíritos malévolos) não o possa reconhecer. Se - nome do falecido é tirado de uma planta, da água, do fogo, etc., estas designações deixam der ser usadas; empregam-se substitutos.

Para os Goajiros (Colômbia), pune-se quase sempre com a morte, ou multa, geralmente de dois ou mais bois.

Entre os Terenos (sul de Mato Grosso), "quando um dos pais morre, todos os filhos recebem novos nomes, para que o pai sobrevivente não se lembre do passado por meio dos antigos apelidos e para que, assim, não se entristeça" (128).

Entre os Cadiuéus (sul de Mato Grosso), "quando alguém morre', seu nome não pode ser mais pronunciado, até que um neto ou bisneto o retome. Os nomes portuguêses adotados pelos Cadiuéu... são usados sòmente nas relações com estranhos e não mudam com a morte de parentes, hoje êles têm uma nova utilidade que é permitir falar dos parentes mortos, o que era muito difícil, em virtude de não se poderem referir aos seus nomes tribais. As modificações resultantes da morte de um parente vão além da troca de nome; verificamos que ocorrem mudanças

128. H. BALDUS, Ensaios de Etnologia Brasileira, 1937, p. 71. 
nos próprios têrmos de parentes com que os membros mais intimamente aparentados com o morto se designam reciprocamente" (129).

Os Sérvios não citam o nome de um morto, mas "o que entrou em paz" ou "a aflição" ou ainda "o contente", "o feliz".

Entre os Russos de Olenque, "uma certa pessoa morreu", e os Russos de Tver, referindo-se aos antepassadios dizem: "os justos". bre".

Os Ucranianos assim aludem ao morto: "o perdido", "o po-

Os Japonêses evitam a palavra shi, "quatro", porque colide com o homófono shi que quer dizer "morte". Usam yottsu ou yon ou ainda yo, do outro seu sistema de numeração (130).

Além dos povos citados, evitam os nomes dos mortos - os Lênguas (Grão Chaco), Abipões (Grão Chaco), Guaicuru (sul de Mato Grosso), Samoiedos (Sibéria), Todas (sul da India), Mongóis (Tartária), Ainos (Japão), Acambas e Nândis (leste da África), Tinguianos (Filipinas), Bornéu, Madagáscar, Tasmânia, etc.

Em escritores gregos é freqüente', como "pluralia tantum", os vocábulos que traduzem "morte": phonaí, sphagaí, thánatoi, phónoi, thúmata e sphágia. Trata-se de indeterminação no plural, recurso eufêmico. O singular é evitado.

Verbos referentes à ação de matar são tabus: Os Buriatos, na caça, em vez de "matar o animal", dizem "levar o animal à inércia": em vez de "atirar ao pássaro no vôo", preferem: "descê-lo" ou "fazê-lo vir abaixo". Os Jucaguiros, em vez de "eu matei", dizem "eu achei".

Interessante é o evitamento da voz passiva "ser matado" em hitita. O hitita ak-, "morrer", é substituto do passivo não empre-

129. DARCY RIBEIRO, Religião e Mitologia Kadiuéu, publicaçāo 106 do S. P. I.. Rio, 1950, p. 94. Ver também DARCY RIBEIRO, Sistema Familial Kadiuéu in "Rev. do Museu Paulista", v. II, S. Paulo, 1948, p. 184-185.

130. M. PEI, The Story of Language, p. 249. Cf. LEO MACNINO, I Facili Misteri della Lingua Giapponese, Miláo, 1937, p. 66, nota 3. 
gado do verbo kuen, "matar", do mesmo modo que o grego apothnéskein hupó tinos é usado como passivo de apoktéino, principalmente em sentido jurídico (HAVERS). Caso símile no português, pois matar é mais chocante que morrer, donde, em vez de - êle foi matado a tiros - o uso de êle foi morto a tiros.

Não se permite dizer, entre os Ostíacos, por ocasião da festa do urso - "matamos o urso", porém "o sagrado animal morreu". O uso do verbo intransitivo é, pois, uma expressão atenuante, eufemística, com que se evita "matar" ou "ser matado", ambos violentos.

Em Petrônio consta a designação da "mortalha" sob a forma. vitalia, baseado em vita, "vida", por "eufemismo supersticioso" (131), em vez de mortualia.

\section{8. - TABUS EM NOMES DE ANIMAIS}

Aqui, o tabu é motivado pelo terror que causam as feras, como devoradoras, como venenosas, nocivas às pessoas e coisas (alimentos, plantas, frutos, objetos, etc.); pelo desejo de caçadias ou pescarias felizes; pela crença de que são os animais espíritos malignos, que prejudicam os homens, suas coisas e outros animais; pelo totemismo, crença de que são os animais espíritos malignos, que prejudicam os homens, suas coisas e outros animais; pelo totemismo, crença de que íribos ou indivíduos são descendentes de animais, a quem, portanto, se presta culto, veneração, estima são sagrados (132). Mas a principal razão em que se funda a zoolatria ou a zoofobia, deve ser na semelhança natural que apresentam os animais com o homem. Se há uma tendência em antropomorfizar idéias e atos, muito maior base há, entre os povos naturais e incultos, em encarar os brutos como outros sêres humanos ou como modalidades de homem, porém, visto que diferentes por múltiplos aspectos, são dotados de singulares poderes mágicos ou sobrenaturais.

131. MANUEL DIAZ, Antologia del Latín Vulgar, Madri, 1950, p. 27, nota 7.

132. J. G. FRAZER, O Totemismo, trad., Lisboa, 1913. - M. BESSON, Totemismo, trad., ed. Lábor, 1931. - LEWIS SPENCE, Animales Sagrados in "Maravillas de la Vida Animal". I1, B. Aires e Montevidéu, 1952, p. 1 a 11 . 
Já vem de remota antiguidade a zoolatria, salientando-se 0 Egito, em que se cultuavam o boi, o crocodilo, o macaco, o hipopótamo, o íbis, o escorpiăo, o gato, a rã, etc. Ảs vêzes eram personificados, ou uma divindade nêles se encarnava, como Ápis, reencarnação de Osíris. Ao íbis instituíram culto especial, relacionando-o com a deusa Tote e com a Lua.

Entre os Celtas, Epona - cujo nome se baseia em "epo-, "cavalo" - é a divindade' protetora dos cavalos, etc. Andarta é o urso ("arta); mais tarde deusa da vitória. Moltinus é a divindade-carneiro (" molto-) (133).

$\mathrm{Na}$ India, lembremos a antiqüíssima veneração ao elefante, à vaca, à serpente.

Entre os Bretões, conforme narra César, não se permitia comer lebre, galinha e pato (134).

Tem havido povos cujos etnôminos se originaram de animais, como os Bíbrocos, tribo da Bretanha, que deve o seu nome ao castor ('bebros), ao qual prestavam culto.

Os Hirpos ou Hirpinos eram assim chamados porque, certamente, pretendiam descender de um lôbo (osco hirpus) ou apenas o adoravam.

Ao touro (taurus) devem os Taurinos o seu nome.

Os Picentes são assim chamados porque se relacionam com o picanço (picus).

Os Árcades são homens-ursos (gr. árkos) (134-a).

Pode, todavia, acontecer que etnônimos dessa base se expliquem por apelido de zombaria, de escárnio (135).

Há topônimos que se baseiam em designação de animal, co-

133. G. DOTTIN, La Langue Gauloise, Paris, 1920.

134. Commentarii de Bello Gallico, V, 12.

134-a. A. CARNOY propõe para Árkades outro étimo, i. é, "os loiros", do "pelásgico" (Orbis, t. III, n. ${ }^{\circ} 434$, Lovaina, 1954).

135. F. SOLMSEN, Indogermanische Eigennamen als Spiegel der Kulturgeschichte, Haidelbergue, 1922; p. 107 . Nesta obra citam-se ainda outros etnônimos de base zoonimica. 
mo Leontópolis, no Delta, onde era adorado o leão (gr. léon).

Em tempos recentes e na atualidade, verificamos fatos símiles entre vários povos.

"Os membros duma tribo totêmica, diz J. G. FRAZER, usam o nome do seu totem e julgam-se, geralmente, descendentes naturais dêsse mesmo totem" (136).

Assim, os clãs do urso e do lôbo dos Iroqueses atribuem a sua origem a êsses animais.

Os índios da Califórnia dizem-se descendentes dos coiotes.

O clã da carpa,entre os Uatacos (América do Norte), proveio dos ovos de uma carpa.

Os clãs dos Araucos (Güiana) são descendentes de animais, aves, plantas, cujos nomes usam.

Em Senegâmbia, cada família descende de um animal - hipopótamo, crocodilo, escorpião, etc.

Em algumas tribos australianas é vedado aos homens comerem a carne do animal que pertença à sua classe, considerado irmão.

Os Oraõe's (povo dravídico do noroeste da India) têm totens Parciais, i. é, a cabeça de uma tartaruga, o ventre de um porco, etc., e, neste caso, tais partes não podem ser comidas.

Em certos povos ou tribos é proibido tocar no totem, ou numa das suas parte's, e às vêzes, se veda o simples olhar para êle.

Os membros do clá do crocodilo, entre os Bechuanas (África do sul), chamam pai ao crocodilo, e invocam-no nos juramentos.

Os Bororos têm muitos ascendentes animais: o jaguar, a anta, o tatu-canastra, a tartaruga, a arara vermelha, etc. (137). landia.

O martim-pescador é a ave sagrada dos Máoris, Nova Ze-

136. O Totemismo, trad., Lisboa, 1913, p. 7.
137. P. ANTONIO COLBACCHINI e P. CÉSAR ALBISETTI. Os Bororos Orientais, Brasiliana, 1942, p. 30-31. 
Os Guaicurus reconhecem, como seu criador, o caracará.

Os Tupinambás tinham receio supersticioso por certos animais, como o matim-tapirera, mensageiro dos parentes falecidos (138).

As diversas formas dêsse nome levam-nos a admitir, provàvelmente, um disfarçado encobrimento tabuístico: tapererê, pererê, matinta, małi, saperê, sarerê. Estas últimas são devidas ao sinônimo saci-pererê, que causou também saci-cererê, saci-saperê e saci-sia-Teresa. Na maioria das lendas tupis, apresenta-se sob a forma de pássaro (139).

O acuti-puru é um mamífero roedor sob a qual forma a alma humana sobe ao céu, após o apodrecimento (140).

Como uma das crendices de Cuiabá, KARL VON DEN STEINEN cita o "diabo-mor" sob a forma de bode, boi, sapo ou rã (141).

Entre os Bacairis, o feiticeiro se transforma em animal (142).

Os Bororos usam, em seus cantos de caráter sagrado, nomes de animais e de coisas diversos dos da língua corrente. Assim, p. ex., a anta é chamada mariddo, exerae, etc., em vez de ki (143).

Os Mbiás, indígenas guaranis, utilizam nomes secretos para referir-se a animais, quando supōem estejam perto, a fim de não se assustarem e fugirem (144).

Os Pancas, sul de Mirzapur, Ásia, não chamam com seu nome o tigre, o urso, o camelo e o burro. Ao camelo dizem: "o pescoço comprido". Outras tribos da mesma regiaao têm êsse escrúpulo apenas de manhã (FRAZER).

138. ARTUR RAMOS, Introd. à Antropologia Bras., I, Rio, 1943, p. 122-123.

139. OSVALDO ORICO, Mitos Ameríndios, S. Paulo, 1930, p. 151.

140. E. STRADELLI, Vocabulários da Língua Ceral, Rio, 1929, s. v.

141. Entre os Aborigines do Brasil Central, trad., S. Paulo, 1940, p. 703.

142. K. VON DEN STEINEN, o. c., p. 466

143. COLBACCHINI - ALBISETTI. Os Bororos Orientais, 1942, p. 360-361.

144. L. CÁDOGAN, La Lengua Mbyá-Cuarani in "Bol. de Filología", t. V, ns. 40, 41, 42, Montevidéu, 1949, p. 668-669. 
Os Cáuares (Kharwars), tribo dravídica, se abstêm de proferir, de manhã, o nome de vários animais - porco, esquilo, lebre, chacal, urso, macaco, burro. Usam outros têrmos, como, p. ex., "a que tem quatro patas", "a que se esconde nas rochas" (lebre); "aquêle cujo fígado é compassivo" (urso); etc.

Se os Buiares (India) são obrigados a falar, de manhã, num macaco, dizem "o trepador de árvores"; para o urso dizem "o comedor de formigas brancas". Não pronunciam a palavra "crocodilo".

Em certas regiões de Sonda, o javali é o "belo".

Os Queniaques (Bornéu) temem dizer "o crocodilo"; em vez disto, proferem "o avô velho".

Os Malaios dão o nome de "o príncipe" ao gamo; "o imperador da floresta" ao cabrito; "o corpulento que olha atrás" ao elefante.

Os nativos de Java, quando vigiam as plantações para protegê-las contra os javalis, falam dêstes como "homens belos".

Os Estonianos acreditam que as feras não fazem tanto mal, Se se lhes designam por outros nomes.

Entre os Esquimós da Terra de Bafim, as mulheres, em luto, evitam o nome de qualquer animal.

Em certas partes da Alemanha é proibido chamar certos animais por seus nomes entre o Natal e a Epifania (FRAZER).

Na itha de Sejer (Mar do Norte), entre o Natal e o Ano Novo, conforme JESPERSEN (145), não se fala de ratos, pulgas e piolhos, porque, então, haverá proliferação dos mesmos.

$\mathrm{Na}$ Jutlândia ensina-se às crianças a dizer "o grande" em vez de "piolho"; de outro modo, aparecerão muitos (Jespersen). O albanês fangi, "aranha venenosa", é um abreviamento de caráter tabuístico, do grego phalángion, "tarântula" (Havers).

(Continua)

145. Humanidad, Nación, Individuo, p. 228. 


\section{ADENDA:}

Ao cap. 12 (Tabus em nomes de espíritos malignos):

Em uma epigrafia tumular de Évora, Portugal (séc. VII ou VIII), o demônio é chamado tiramnus antiquus, "tirano antigo" (Pe. Miguel de Oliveira, Epigrafia Cristã em Portugal, Lisboa, 1941, p. 48).

Ao cap. 17 (Tabus em nomes de mortos):

Entre os Mundurucus há uma expressão especial para designar os mortos - "nós nenhum" ou "nós ninguém" (C. Strömer, O. F. M., Die Sprache der Mundurukú, 1952, p. 108).

Com a expressão vixit, "viveu", os Romanos anunciavam a morte de alguém (A. Resende, Frases e Curiosidades Latinas, 3.a ed., Rio, 1936). Há citação de Plauto no Dic. Latino-Port. de Saraiva (s. v.).

No Brasil, popularmente, a morte é denominada a magra.

São numerosas as frases-feitas sinonímicas de "morrer", algumas de evidente cunho literário, outras populares, e muitas, provàvelmente, criadas sob inspiração eufêmica:

Terminar a carreira, partir para outro mundo, partir para outro mundo melhor, entregar a alma, entregar a alma a Deus, seguir para outro mundo, seguir para o grande desconhecido, embarcar para outro mundo, fazer a vontade da morte, ser riscado do número dos vivos, ser roubado à familia, ser roubado aos amigos, exalar o último suspiro, passar para além-túmulo, ir para além-túmulo, viajar para as trevas, baixar à sepultura, passar no barco de Caronte, atravessar o Styx, descer à morada de Plutão, ter o fio da vida cortado pela Parca, fechar as pálpebras, perder a vida, entrar na noite eterna, entrar no grande mistério, deixar o mundo inferior, voltar à terra, tornar-se pó, reunir-se aos antepassados, despachar-se ao outro mundo, entrar na imortalidade, ser chamado por Deus, ser chamado para outro mundo, render a guarda, passar a arma para a esquerda, sair do cenário do mundo, deixar esta vida, sair do cenário, abandonar êste mundo, ete. 